\title{
Delirium hos eldre pasienter
}

BAKGRUNN Delirium, «akutt forvirring», er en vanlig og alvorlig komplikasjon til akutt sykdom, særlig hos eldre. Belastningen er stor for pasient, pårørende og helsetjenesten. Formålet med artikkelen er å gi helsepersonell som håndterer delirium oppdatert informasjon om tilstanden.

\section{KUNNSKAPSGRUNNLAG Artikkelen bygger på et litteratursøk i PubMed kombinert med artikler fra eget litteraturarkiv og egne kliniske erfaringer.}

RESULTATER Delirium er en alvorlig akuttmedisinsk tilstand som ofte overses hos eldre. Prevalensen er anslått til 11-42\% hos eldre pasienter i medisinske avdelinger og nær 50 \% hos pasienter med hoftebrudd. Prevalensen er trolig også høy i sykehjem, men dette er dårligere kartlagt. Høy alder og demens er de viktigste risikofaktorene. Traumer, infeksjoner, hjerneslag og metabolske forstyrrelser er de vanligste utløsende faktorene. Patofysiologien er dårlig kartlagt, og de medikamentelle behandlingsmulighetene er få og lite studert. Delirium er forbundet med økt risiko for demens, funksjonstap og død. Kortvarig bruk av lavdoseantipsykotika er førstevalget, men er kontraindisert hos pasienter med parkinsonistiske syndromer.

FORTOLKNING Påvisning og behandling av utløsende årsak må ha høy prioritet ved delirium. Ikke-medikamentelle tiltak er viktigst for å forebygge og behandle tilstanden.

Delirium, ofte kalt «akutt forvirring», kjennetegnes av raskt innsettende endringer $\mathrm{i}$ bevissthetsnivået, med oppmerksomhetssvikt og kognitive forstyrrelser, eventuelt også persepsjonsforstyrrelser (1). Tilstanden har en tendens til å fluktuere gjennom døgnet. Delirium er vanlig hos eldre og medfører store belastninger for pasienter, pårørende $o g$ helsetjenesten. Vårt inntrykk er at kunnskapen om delirium er mangelfull i mange kliniske miljøer. Hensikten med artikkelen er derfor å gi oppdatert informasjon til helsepersonell som håndterer denne tilstanden.

\section{Kunnskapsgrunnlag}

Vi har gjort et litteratursøk i PubMed for perioden 1.1.2000-1.10. 2012, med søkeord «delirium», noe som ga 5516 treff. For lettere å kunne sortere treffene ble søket kombinert med ulike søkeord: «elderly», «risk factors», «prevention», «treatment», «pathophysiology», «prognosis». Ut fra dette plukket vi skjønnsmessig ut artikler og supplerte disse med artikler fra eget litteraturarkiv samt egen klinisk erfaring i feltet.

\section{Diagnostiske kriterier}

De diagnostiske kriteriene for delirium fra det amerikanske psykiatriske diagnosesystemet Diagnostic and Statistic Manual (DSM)-IV er gjengitt i ramme 1 (2). Pasientenes psykomotoriske tempo er forstyrret og kan være for høyt, for lavt eller vekslende. Pasienter med for høyt psykomotorisk tempo sies å ha et hyperaktivt eller agitert delirium, og er urolige og ofte hallusinerte. De med hypoaktivt eller «stille» delirium er psykomotorisk langsomme, initiativløse og gjerne somnolente. Hypoaktivt delirium passerer ofte udiagnostisert, men kan ha en særlig dårlig prognose (3).

Pasienter som ikke fullt tilfredsstiller kriteriene for delirium, men har ett eller flere av symptomene, sies gjerne å ha et subsyndromalt delirium (4). Dersom et delirium ikke går over når underliggende tilstander er adekvat behandlet, brukes gjerne betegnelsen persisterende delirium (5), som kan vare $\mathrm{i}$ flere måneder og ledsages av økt mortalitet og svekket funksjon og kognisjon.

\section{Diagnostikk}

Delirium, særlig den hypoaktive varianten, er underdiagnostisert (6). Dette kan skyldes manglende kunnskap, mistolking av delirium som demens eller depresjon, manglende erfaring i kognitiv vurdering eller manglende kjennskap til pasientens premorbide kognitive funksjonsnivå. Viktige kjennetegn er rask debut, svingende forløp, endret bevissthetsnivå og sviktende oppmerksomhet.

Diagnosen baseres på sykehistorien, kliniske observasjoner og kognitiv vurdering (2). Opplysninger fra pårørende eller pleiepersonell er avgjørende og kan ofte gi svar på om tilstanden har endret seg raskt eller gradvis. Det mest brukte diagnostiske hjelpemidlet er Confusion Assessment Method (CAM) (fig 1) $(7,8)$. Det finnes også en variant til bruk hos intuberte pasienter, kalt CAMIntensive Care Unit (CAM-ICU) (9). En valid skåring forutsetter god kunnskap om pasienten og god opplæring. Enkle tester for oppmerksomhet er viktige i diagnostikken,

\author{
Bjørn Erik Neerland \\ bjorn.erik@neerland.net \\ Institutt for klinisk medisin \\ Universitetet i Oslo \\ Leiv Otto Watne \\ Torgeir Bruun Wyller \\ Institutt for klinisk medisin \\ Universitetet i Oslo \\ og \\ Geriatrisk avdeling \\ Oslo universitetssykehus \\ Se også kunnskapsprøve \\ på www.tidsskriftet.no/quiz
}

\section{HOVEDBUDSKAP}

Delirium er en sannsynlig underdiagnostisert tilstand med dårlig prognose, personlige lidelser og samfunnsmessige kostnader

Delirium kan ofte forebygges og behandles med ikke-medikamentelle og tverrfaglige tiltak

Forebyggende medikamentell behandling anbefales ikke

Foretrukket medikamentell behandling ved hyperaktivt delirium er lavdoseantipsykotika, men risiko for uheldige effekter må overveies nøye 
som f.eks. å be pasienten repetere en vilkårlig tallrekke (fem siffer) forlengs og baklengs eller å ramse opp ukedagene eller årets måneder baklengs (10).

\section{Forekomst}

Forekomsten øker med alderen og er rapportert til å være $11-42 \%$ hos pasienter 65 år eller eldre innlagt i sykehus (11). Hos akuttinnlagte pasienter med demens er prevalensen rundt $50 \%$ (12), og det samme gjelder for pasienter med hoftebrudd $(1,13)$. Blant pasienter 65 år eller eldre $\mathrm{i}$ intensivavdelinger kan forekomsten være $70 \%$ eller mer (14). Forekomsten i sykehjem er antakelig også høy, men er langt dårligere undersøkt (15).

Risikofaktorer og utløsende faktorer Årsakene til delirium er multifaktorielle og innebærer komplekse interaksjoner mellom predisponerende og utløsende faktorer (tab 1, fig 2) (16, 17). I prinsippet kan enhver akutt somatisk sykdom utløse delirium. Risiko for postoperativt delirium påvirkes i tillegg av det operative inngrepets størrelse og varighet, preoperativ ventetid, postoperativ smerte og komplikasjoner samt bruk av sedativer (18).

\section{Prognose}

Delirium gir økt komplikasjonsrisiko og er vist å være en selvstendig risikofaktor for død, demens, tap av funksjon i dagliglivets aktiviteter (Activities of Daily Living, ADL), sykehjemsbehov og forlenget sykehusopphold (19-21). For pasienter med kjent demens ser det ut til at det å gjennomgå et delirium ytterligere akselererer det kognitive funksjonstapet (22).

\section{Patofysiologi}

Patofysiologien ved delirium er dårlig kartlagt. Det er argumentert for en inndeling i to etiologiske hovedgrupper (23):

- fysiologiske avvik som gir direkte hjernepåvirkning, f.eks. hypoksi, hypotensjon, hypoglykemi, anemi, traume, infeksjoner i sentralnervesystemet og elektrolyttforstyrrelser.

- «uhensiktsmessige stressresponser». Stressresponsene kan formidles både gjennom hypofyse-binyre-aksen (kortisol og ACTH), det sympatiske nervesystemet (acetylkolin, noradrenalin, adrenalin) og gjennom inflammasjonssystemet (cytokiner).

En sentral hypotese er at endret nevrotransmisjon, særlig svekket kolinerg transmisjon og/eller overaktivitet i dopaminerge baner, kan gi delirium. Også andre nevrotransmittere, f.eks. GABA, noradrenalin, 5-hydroksytryptamin og glutamat, har vært foreslått, men dette er dårligere studert (24). En annen hypotese er at delirium skyldes nevroinflammasjon. Traumer eller akutte sykdommer gir økt produksjon av proinflammatoriske cytokiner som både kan passere blod-hjerne-barrieren, aktivere mikroglia, forårsake nevroinflammasjon og påvirke omsettingen av nevrotransmittere $(25,26)$. Imidlertid er ingen av de patofysiologiske hypotesene særlig godt underbygd.

\section{RAMME 1}

Diagnostiske kriterier for delirium fra det amerikanske psykiatriske diagnosesystemet Diagnostic and Statistic Manual IV (DSM-IV) (2). Alle kriteriene kreves oppfylt

A Forstyrret bevissthet med nedsatt evne til å fokusere, opprettholde og endre oppmerksomheten, særlig i relasjon til stimuli fra omgivelsene

B Forstyrret kognisjon (særlig redusert hukommelse, desorientering eller påvirket talefunksjon) eller utvikling av persepsjonsforstyrrelser som ikke kan forklares av en allerede kjent demenstilstand

C Akutt debut (timer, dager) av symptomer som fluktuerer gjennom døgnet og fra dag til dag

D Fra anamnese, klinisk undersøkelse og/eller laboratorieundersøkelser kan en eller flere etiologiske faktorer identifiseres

\section{Ikke-medikamentelle tiltak}

Forebygging er mest effektivt for å redusere forekomst og konsekvenser av delirium. Dette krever en multifaktoriell og tverrfaglig tilnærming. Man må identifisere pasienter med forhøyet risiko, og tiltakene må være målrettede og tilpasset pasientens risikofaktorer. Egne programmer for slike tiltak er angitt å gi en $40 \%$ relativ risikoreduksjon

\begin{tabular}{|c|c|c|}
\hline AKUTT DEBUT OG VEKSLENDE FORL $\varnothing P$ & & Boks 1 \\
\hline $\begin{array}{l}\text { Finnes det tegn på akutte endringer i pasientens mentale tilstand i } \\
\text { forhold til hvordan han/hun er til vanlig? }\end{array}$ & $\square \quad$ Nei & $\square \mathrm{Ja}$ \\
\hline $\begin{array}{l}\text { Vekslet den (unormale) atferden i løpet av dagen, dvs, hadde tegnene en } \\
\text { tendens til å komme og gå eller } \varnothing \text { ke eller avta i styrke? }\end{array}$ & $\square \quad$ Nei & \multirow[t]{2}{*}{$\square \mathrm{Ja}$} \\
\hline UOPPMERKSOMHET & & \\
\hline $\begin{array}{l}\text { Hadde pasienten problemer med å holde oppmerksomheten, for } \\
\text { eksempel ble han/hun lett distrahert, eller hadde han/hun problemer } \\
\text { med å få med seg det som ble sagt? }\end{array}$ & $\square \quad$ Nei & $\square \quad \mathrm{Ja}$ \\
\hline DESORGANISERT TANKEGANG & & Boks 2 \\
\hline $\begin{array}{l}\text { Var pasientens tankegang desorganisert eller usammenhengende, for } \\
\text { eksempel, usammenhengende eller irrelevant konversasjon, uklare eller } \\
\text { ulogiske tankerekker, uforutsigbar endring fra tema til tema? }\end{array}$ & $\square \quad \mathrm{Nei}$ & $\square \mathrm{Ja}$ \\
\hline \multicolumn{2}{|l|}{ ENDRET BEVISSTHETSNIVÅ } & \\
\hline \multicolumn{2}{|l|}{ Generelt sett, hvordan vurderer du pasientens bevissthetsnivå? } & \\
\hline$\square \quad$ Våken & & \\
\hline$\square \quad$ Oppspilt (anspent) & & \\
\hline$\square \quad$ Somnolent (søvnig, lett å vekke) & & \\
\hline Stuporøs (omtåket, vanskelig å vekke) & & \\
\hline$\square \quad$ Komat $\varnothing$ s (umulig å vekke) & & \\
\hline Er det noen kryss i denne boksen? & $\mathrm{Nei}$ & $\square$ \\
\hline
\end{tabular}

Figur 1 Faksimile av Confusion Assessment Method (CAM), algoritmeversjon. Hvis alle punktene i boks 1 og minst ett iboks 2 er avmerket, er diagnosen delirium sannsynlig. Gjengitt fra (7), med tillatelse. Norsk oversettelse ved Anette Hylen Ranhoff, Marianne Jensen Hjermstad og Jon Håvard Loge, 2004 (8) 
Tabell 1 Vanlige risikofaktorer og utløsende faktorer for delirium

\begin{tabular}{ll} 
Vanlige risikofaktorer & Vanlige utløsende faktorer \\
Høy alder & Hoftebrudd \\
Kognitiv svikt/demens & Kirurgiske inngrep \\
Depresjon & Infeksjon \\
Tidligere gjennomgått delirium & Hjerneslag \\
Omfattende komorbiditet & Akutt koronarsyndrom \\
Sansesvikt & Dehydrering \\
Lav kroppsmasse & Metabolske forstyrrelser \\
& Smerter \\
\hline
\end{tabular}

for delirium (27). Viktige forebyggende tiltak er gjengitt i tabell $2(1,27,28)$. Det er avgjørende at man sikrer opplæring av helsepersonell og setter tiltakene i system. Bruk av akuttgeriatriske enheter til disse pasientene kan redusere forekomsten av delirium og gi kortere liggetid (29). Et strukturert samarbeid mellom ortopeder og et tverrfaglig geriatrisk team ser ut til å kunne gi lavere forekomst av delirium hos hoftebruddspasienter (30).

Når diagnosen delirium er stilt, er det avgjørende å identifisere og behandle underliggende årsak(er) raskt. Dette krever en bred diagnostisk tilnærming. Man må være

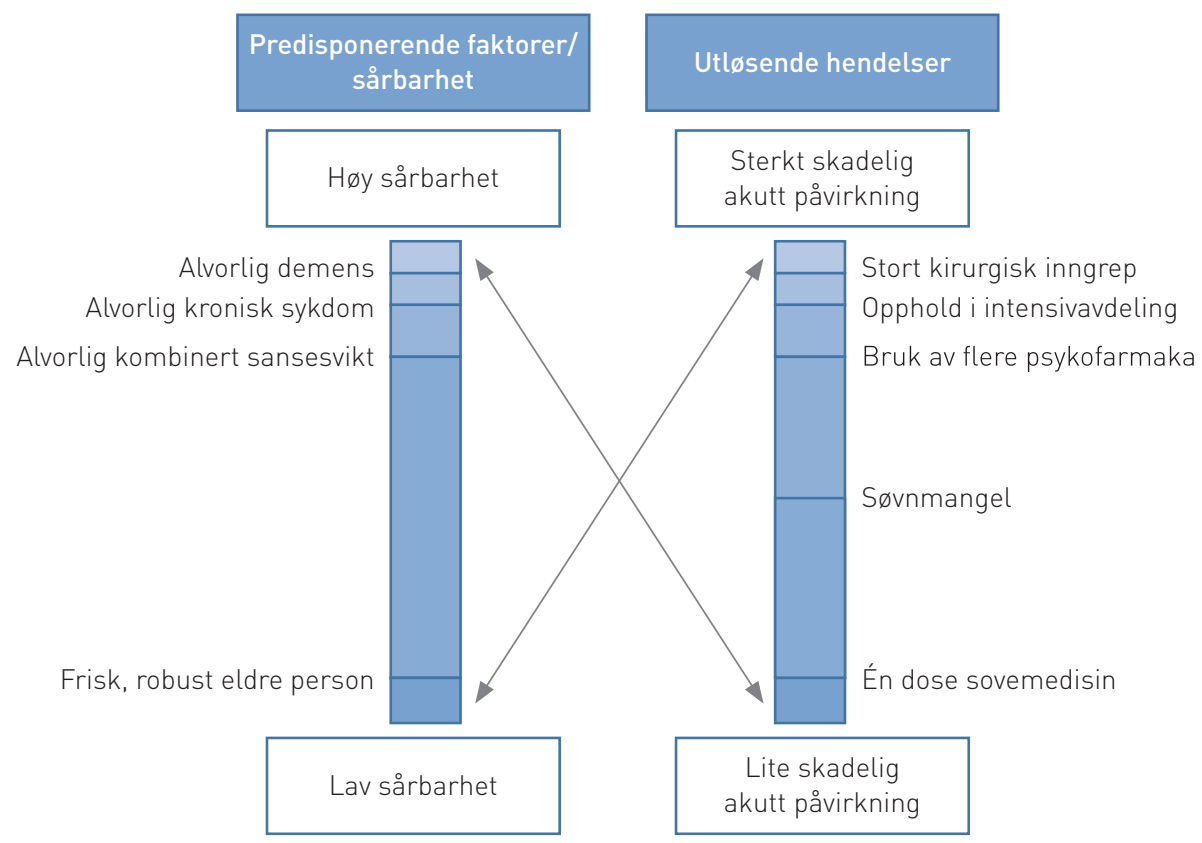

Figur 2 Skjematisk fremstilling av sammenhengen mellom utløsende faktorer og sårbarhet. En skrøpelig pasient med mange risikofaktorer kan utvikle delirium ved bare lett ytre belastning. For mer robuste pasienter skal det kraftigere akutt påvirkning til. Jo mer sårbar pasienten er, desto mindre fysiologiske avvik skal altså til for å utløse et delirium. Figur basert på illustrasjon av Deborah Maizel (17). Gjengitt og oversatt med tillatelse har lenge vært foretrukket behandling (31). Denne anbefalingen er imidlertid basert på svært sparsomme data. Det samme gjelder for behandling med nyere antipsykotiske midler. Disse er i noen grad blitt sammenliknet med haloperidol, men ikke med placebo.

For pasienter med hoftebrudd fant man at forebyggende behandling med $1,5 \mathrm{mg}$ haloperidol daglig ikke hadde effekt på forekomst av delirium, men reduserte både alvorlighetsgrad og varighet av tilstanden (32). Det er vist redusert forekomst av delirium og kortere opphold $\mathrm{i}$ intensivavdeling hos pasienter som fikk kontinuerlig infusjon med lavdose haloperidol i 12 timer i forbindelse med omfattende kirurgiske inngrep (33).

En studie med 30 unge pasienter med aids viste at både haloperidol og klorpromazin ga en bedring i symptomer sammenliknet med lorazepam, men man sammenliknet ikke med placebo (34). Gyldigheten av å generalisere dette funnet til eldre pasientgrupper med delirium er tvilsom. Nyere antipsykotika, som risperidon (35-38), olanzapin (38-41), quetiapin (42) og ziprasidon (43), har $\mathrm{i}$ enkeltstudier vist omtrent tilsvarende effekt på delirium som haloperidol.

Preoperativ behandling med kolinesterasehemmerne donepezil $(44,45)$ eller rivastigmin (46) har ikke vist noen gunstig effekt. Det er heller ingen holdepunkter for at behandling med kolinesterasehemmere har effekt ved etablert delirium. En placebokontrollert multisenterstudie av rivastigmin hos intensivpasienter ble stoppet fordi man fant en trend i retning av høyere mortalitet og lenger varighet av delirium i behandlingsgruppen (47). En svært liten studie viste ingen effekt av rivastigmin sammenliknet med placebo på varighet av delirium (48).

Klometiazol (Heminevrin) brukes tradisjonelt for å oppnå sedasjon og søvn, men er ikke studert hos pasienter med ikke-alkoholisk delirium. Medikamentet er forbundet med en rekke uheldige bivirkninger, som respiratorisk og kardiovaskulær depresjon $(49,50)$. Det bør brukes med forsiktighet, reserveres for pasienter som er hemodynamisk og respiratorisk stabile, og bare om kvelden for å oppnå nattesøvn.

Som ledd i en sedativ behandlingsstrategi har man benyttet ulike benzodiazepiner. Denne legemiddelgruppen er ikke studert i placebokontrollerte fors $ø \mathrm{k}$ hos pasienter med ikke-alkoholisk delirium, og man har ingen studier som har vist gunstig effekt på insidens, varighet eller alvorlighetsgrad (51). Det er imidlertid vist at benzodiazepiner gir økt fallrisiko og økt risiko for utvikling, forverring og forlengelse av delirium (52). Det er fare for at bruk av benzodiazepiner blir langvarig, og disse midlene har i utgangspunktet ingen plass $\mathrm{i}$ behandlingen, selv om de ofte brukes for å dempe angst og uro. 
Tabell 2 Viktige ikke-medikamentelle tiltak i forebygging og behandling av delirium. Tiltak bør også gjennomføres etter at diagnosen er stilt $(1,27,28)$

\section{Forebyggende tiltak}

Tidlig mobilisering

Hyppig reorientering og aktivisering

Forebygging av dehydrering

Korreksjon av hypovolemi, hypoksi, anemi, elektrolyttforstyrrelser og feber

Optimalisering av komorbide tilstander

Tilstrekkelig smertelindring

Redusert bruk av psykoaktive medikamenter

Forebygging av søvndeprivasjon

Forebygging av obstipasjon

\section{Behandling}

Passe skjerming av pasienten, med rolige omgivelser og behagelig belysning

Unngå unødige endringer i pasientens omgivelser og personale

Hyppig reorientering

Klokke og kalender

Tilstedeværelse av pårørende

God øyekontakt, hyppig berøring og tydelighet i verbal kommunikasjon

Redusere bruk av ubehagelig utstyr (som intravenøse kanyler og urinkatetere) til et minimum

For hypoaktive pasienter er det særlig aktuelt å forebygge liggesår, aspirasjonspneumoni og dyp venetrombose

Grundig legemiddelgjennomgang

- alle medikamenter som ikke er strengt nødvendige bør seponeres

- intensiver behandlingen av eventuelle tilstander som ikke er godt

kompensert og som kan antas å bidra til å vedlikeholde deliriet

Korreksjon av sansedeprivasjon (briller, høreapparat)

Sedasjon med den alfa-2-adrenerge agonisten deksmedetomidin reduserer insidens og varighet av delirium i intensivavdelinger, sammenliknet med lorazepam (53), midazolam (54) og propofol (55). Behandling med melatonin $0,5 \mathrm{mg}$ daglig i 14 dager var assosiert med lavere risiko for delirium blant medisinske pasienter (56). En pågående, placebokontrollert studie i Nederland evaluerer effekten av profylaktisk behandling med melatonin til pasienter med hoftebrudd (57).

\section{Diskusjon}

Kunnskapsgrunnlaget for delirium er sparsomt, særlig for patofysiologiske forhold og farmakologisk intervensjon. For ikke-medikamentelle tiltak er grunnlaget noe bedre. Vi vil understreke betydningen av vedvarende diagnostisk oppmerksomhet for å kunne iverksette målrettede ikke-medikamentelle behandlingstiltak og utredning ( $\operatorname{tab} 1, \operatorname{tab} 2$ ). $\mathrm{Vi}$ anbefaler at pasienter som utvikler delirium i forbindelse med et akutt sykehusopphold gjennomgår en evaluering av kognisjon og funksjonsnivå etter utskrivningen, når tilstanden for øvrig er stabilisert.

Haloperidol eller olanzapin i lav dose kan muligens brukes forebyggende hos utvalgte pasienter med særlig høy risiko. Både nyere og klassiske (haloperidol) antipsykotika kan ha effekt $\mathrm{i}$ behandlingen, men dokumentasjonen er meget sparsom. Det er ikke vist at ett antipsykotikum er overlegent de andre (58). Ved etablert delirium anbefaler engelske retningslinjer haloperidol i lav dose som første- linjebehandling (28). Alvorlige bivirkninger av antipsykotika er økt risiko for død og kardiovaskulære hendelser, særlig hos pasienter med høy alder, demens og funksjonssvikt. For all antipsykotisk behandling gjelder det at man bør gi én enkelt dose eller noen få doser fremfor å behandle i lang tid. Antipsykotika bør reserveres pasienter med hyperaktivt delirium, særlig dem som har uttalte og persisterende symptomer som plager pasienten selv eller umuliggjør årsaksrettet utredning og/ eller behandling. Pasienter med parkinsonistiske syndromer, inklusive demens med lewylegemer, skal som en hovedregel ikke ha antipsykotiske midler. For hypoaktivt delirium er det ikke vist effekt av medikamenter.

Til tross for at delirium representerer et stort problem, er kunnskapsgrunnlaget usikkert og forskningen sparsom. Mer forskning og bedre kliniske kunnskaper er nødvendig for at pasienter med delirium skal få et bedre behandlingstilbud.

\section{Bjørn Erik Neerland (f. 1976)}

er under spesialisering i indremedisin og geriatri og er klinisk stipendiat.

Forfatter har fylt ut ICMJE-skjemaet og oppgir ingen interessekonflikter.

\section{Leiv Otto Watne (f. 1977)}

er under spesialisering $\mathrm{i}$ indremedisin og geriatri og er stipendiat.

Forfatter har fylt ut ICMJE-skjemaet og oppgir

ingen interessekonflikter.

\section{Torgeir Bruun Wyller (f. 1960)}

er spesialist i indremedisin og geriatri, professor i geriatri og overlege.

Forfatter har fylt ut ICMJE-skjemaet og oppgir følgende interessekonflikter: Han har mottatt forelesningshonorar fra AstraZeneca, Nycomed, Pfizer og Roche for emner knyttet til medikamentell behandling av eldre og har mottatt royalty fra Gyldendal Akademisk for Geriatri - en medisinsk lærebok, som bl.a. omfatter delirium.

\section{Litteratur}

1. Inouye SK. Delirium in older persons. N Engl J Med 2006; 354: 1157-65.

2. Diagnostic and statistical manual of mental disorders: DSM-IV-TR. 4. utg. arlington, VA: American Psychiatric Association, 2000.

3. Meagher DJ, Leonard M, Donnelly S et al. A longitudinal study of motor subtypes in delirium: relationship with other phenomenology, etiology, medication exposure and prognosis. J Psychosom Res 2011; 71: 395-403.

4. Meagher D, Adamis D, Trzepacz P et al. Features of subsyndromal and persistent delirium. $\mathrm{Br} \mathrm{J}$ Psychiatry 2012; 200: 37-44.

5. Cole MG, Ciampi A, Belzile E et al. Persistent delirium in older hospital patients: a systematic review of frequency and prognosis. Age Ageing 2009; 38: 19-26.

6. Inouye SK, Foreman MD, Mion LC et al. Nurses recognition of delirium and its symptoms: comparison of nurse and researcher ratings. Arch Intern Med 2001; 161: 2467-73.

7. Inouye SK, van Dyck CH, Alessi CA et al. Clarifying confusion: the confusion assessment method. A new method for detection of delirium. Ann Intern Med 1990; 113: 941-8

8. Nevro-NEL. Cam skåringsskjema for delir. http://nevro.legehandboka.no/skaringsskjema/ cam-skaringsskjema-for-delir-35785.html (31.5.2013). 
9. Ely EW, Margolin R, Francis J et al. Evaluation of delirium in critically ill patients: validation of the Confusion Assessment Method for the Intensive Care Unit (CAM-ICU). Crit Care Med 2001; 29: 1370-9.

10. Hall RJ, Meagher DJ, MacLullich AM. Delirium detection and monitoring outside the ICU. Best Pract Res Clin Anaesthesiol 2012; 26: 367-83.

11. Siddiqi N, House AO, Holmes JD. Occurrence and outcome of delirium in medical in-patients: a systematic literature review. Age Ageing 2006; 35: $350-64$.

12. Korevaar JC, van Munster BC, de Rooij SE. Risk factors for delirium in acutely admitted elderly patients: a prospective cohort study. BMC Geriatr 2005; 5: 6 .

13. Julieb $\varnothing$ V, Bjøro K, Krogseth M et al. Risk factors for preoperative and postoperative delirium in elderly patients with hip fracture. J Am Geriatr Soc 2009; 57: 1354-61.

14. McNicoll L, Pisani MA, Zhang Y et al. Delirium in the intensive care unit: occurrence and clinical course in older patients. J Am Geriatr Soc 2003; 51: $591-8$.

15. McCusker J, Cole MG, Voyer P et al. Prevalence and incidence of delirium in long-term care. Int J Geriatr Psychiatry 2011; 26: 1152-61.

16. Fong TG, Tulebaev SR, Inouye SK. Delirium in elderly adults: diagnosis, prevention and treatment. Nat Rev Neurol 2009: 5: 210-20.

17. Inouye SK. Predisposing and precipitating factors for delirium in hospitalized older patients. Dement Geriatr Cogn Disord 1999; 10: 393-400.

18. Vasilevskis EE, Han JH, Hughes CG et al. Epidemiology and risk factors for delirium across hospital settings. Best Pract Res Clin Anaesthesiol 2012: 26: $277-87$

19. Krogseth M, Wyller TB, Engedal K et al. Delirium is an important predictor of incident dementia among elderly hip fracture patients. Dement Geriatr Cogn Disord 2011; 31: 63-70.

20. Davis DH, Muniz Terrera G, Keage H et al. Delirium is a strong risk factor for dementia in the oldestold: a population-based cohort study. Brain 2012; 135: $2809-16$.

21. Witlox J, Eurelings LS, de Jonghe JF et al. Delirium in elderly patients and the risk of postdischarge mortality, institutionalization, and dementia: a meta-analysis. JAMA 2010; 304: 443-51.

22. Fong TG, Jones RN, Shi $P$ et al. Delirium accelerates cognitive decline in Alzheimer disease. Neurology 2009; 72: 1570-5.

23. Maclullich AM, Ferguson KJ, Miller T et al. Unravelling the pathophysiology of delirium: a focus on the role of aberrant stress responses. J Psychosom Res 2008; 65: 229-38.

24. Hughes CG, Patel MB, Pandharipande PP. Pathophysiology of acute brain dysfunction: what's the cause of all this confusion? Curr Opin Crit Care 2012; 18: 518-26.

25. van Gool WA, van de Beek D, Eikelenboom P. Systemic infection and delirium: when cytokines and acetylcholine collide. Lancet 2010; 375: 773-5

26. Cerejeira J, Firmino H, Vaz-Serra A et al. The neuroinflammatory hypothesis of delirium. Acta Neuropathol 2010: 119: 737-54.

27. Inouye SK, Bogardus ST Jr, Charpentier PA et al. A multicomponent intervention to prevent delirium in hospitalized older patients. N Engl J Med 1999; 340: 669-76.

28. Young J, Murthy L, Westby M et al. Diagnosis, prevention, and management of delirium: summary of NICE guidance. BMJ 2010; 341: c3704

29. Naughton BJ, Saltzman S, Ramadan F et al. A multifactorial intervention to reduce prevalence of delirium and shorten hospital length of stay. J Am Geriatr Soc 2005; 53: 18-23.

30. Marcantonio ER, Flacker JM, Wright RJ et al. Reducing delirium after hip fracture: a randomized trial. J Am Geriatr Soc 2001; 49: 516-22.

31. Ranhoff AH. Medikamentell behandling av delirium hos eldre. Tidsskr Nor Lægeforen 2004; 124 3072-4.

32. Kalisvaart KJ, de Jonghe JF, Bogaards MJ et al. Haloperidol prophylaxis for elderly hip-surgery patients at risk for delirium: a randomized placebo-controlled study. J Am Geriatr Soc 2005; 53 : $1658-66$.

33. Wang W, Li HL, Wang DX et al. Haloperidol prophylaxis decreases delirium incidence in elderly patients after noncardiac surgery: a randomized controlled trial. Crit Care Med 2012; 40: 731 -9.

34. Breitbart W, Marotta R, Platt MM et al. A doubleblind trial of haloperidol, chlorpromazine, and lorazepam in the treatment of delirium in hospitalized AIDS patients. Am J Psychiatry 1996; 153: $231-7$.

35. Prakanrattana U Prapaitrakool S. Efficacy of risperidone for prevention of postoperative delirium in cardiac surgery. Anaesth Intensive Care 2007; 35: 714-9.

36. Hakim SM, Othman AI, Naoum DO. Early treatment with risperidone for subsyndromal delirium after on-pump cardiac surgery in the elderly: a randomized trial. Anesthesiology 2012; 116 : 987-97.

37. Han CS, Kim YK. A double-blind trial of risperidone and haloperidol for the treatment of delirium. Psychosomatics 2004; 45: 297-301.

38. Grover S, Kumar V, Chakrabarti S. Comparative efficacy study of haloperidol, olanzapine and risperidone in delirium. J Psychosom Res 2011; 71: 277-81.

39. Larsen KA, Kelly SE, Stern TA et al. Administration of olanzapine to prevent postoperative delirium in elderly joint-replacement patients: a randomized controlled trial. Psychosomatics 2010; 51: 409-18.

40. Skrobik YK, Bergeron N, Dumont M et al. Olanzapine vs haloperidol: treating delirium in a critical care setting. Intensive Care Med 2004; 30: 444-9.

41. Hu H. Deng W, Yang H. A prospective random control study comparison of olanzapine and haloperidol in senile delirium. Chongqing Med J 2004; 8 : 1234-7.

42. Tahir TA, Eeles E, Karapareddy $V$ et al. A randomized controlled trial of quetiapine versus placebo in the treatment of delirium. J Psychosom Res 2010; 69: 485-90.

43. Girard TD, Pandharipande PP, Carson SS et al. Feasibility, efficacy, and safety of antipsychotics for intensive care unit delirium: the MIND randomized, placebo-controlled trial. Crit Care Med 2010; 38: $428-37$

44. Liptzin B, Laki A, Garb JL et al. Donepezil in the prevention and treatment of post-surgical delirium. Am J Geriatr Psychiatry 2005; 13: 1100-6.

45. Sampson EL, Raven PR, Ndhlovu PN et al. A ran- domized, double-blind, placebo-controlled trial of donepezil hydrochloride (Aricept) for reducing the incidence of postoperative delirium after elective total hip replacement. Int J Geriatr Psychiatry 2007; 22: 343-9.

46. Gamberini M, Bolliger D, Lurati Buse GA et al. Rivastigmine for the prevention of postoperative delirium in elderly patients undergoing elective cardiac surgery-a randomized controlled trial. Crit Care Med 2009; 37: 1762-8.

47. van Eijk MM, Roes KC, Honing ML et al. Effect of rivastigmine as an adjunct to usual care with haloperidol on duration of delirium and mortality in critically ill patients: a multicentre, double-blind, placebo-controlled randomised trial. Lancet 2010 ; 376: 1829-37.

48. Overshott R, Vernon M, Morris J et al. Rivastigmine in the treatment of delirium in older people: a pilot study. Int Psychogeriatr 2010; 22: 812-8.

49. Pentikäinen PJ, Valtonen VV, Miettinen TA. Deaths in connection with chlormethiazole (heminevrin) therapy. Int J Clin Pharmacol Biopharm 1976; 14 : 225-30.

50. Buckley NA, McManus PR. Changes in fatalities due to overdose of anxiolytic and sedative drugs in the UK (1983-1999). Drug Saf 2004: 27: 135-41.

51. Lonergan E, Luxenberg J, Areosa Sastre A et al. Benzodiazepines for delirium. Cochrane Database Syst Rev 2009; nr. 4: CD006379.

52. Pandharipande P Shintani A, Peterson J et al Lorazepam is an independent risk factor for transitioning to delirium in intensive care unit patients. Anesthesiology 2006; 104: $21-6$.

53. Pandharipande PP, Pun BT, Herr DL et al. Effect of sedation with dexmedetomidine vs lorazepam on acute brain dysfunction in mechanically ventilated patients: the MENDS randomized controlled trial. JAMA 2007; 298: 2644-53.

54. Riker RR, Shehabi Y, Bokesch PM et al. Dexmedetomidine vs midazolam for sedation of critically ill patients: a randomized trial. JAMA 2009; 301 489-99.

55. Maldonado JR, Wysong A, van der Starre PJ et al. Dexmedetomidine and the reduction of postoperative delirium after cardiac surgery. Psychosomatics 2009; 50: 206-17.

56. Al-Aama T, Brymer C, Gutmanis I et al. Melatonin decreases delirium in elderly patients: a randomized, placebo-controlled trial. Int J Geriatr Psychiatry 2011; 26: 687-94.

57. de Jonghe A, van Munster BC, van Oosten HE et al. The effects of melatonin versus placebo on delirium in hip fracture patients: study protocol of a randomised, placebo-controlled, double blind trial. BMC Geriatr 2011; 11: 34

58. Lonergan E, Britton AM, Luxenberg J et al. Antipsychotics for delirium. Cochrane Database Syst Rev 2007; nr. 2: CD005594.

Mottatt 9.11. 2012, første revisjon innsendt 10.4 2013, godkjent 3.6. 2013. Medisinsk redaktør Are Brean. 